\title{
Examine your LENS: A Tool for Interpreting Cultural Differences
}

\section{Tracy Rundstrom Williams \\ Texas Christian University}

\section{Introduction}

One of the most commonly cited reasons students choose to study abroad is to experience a new culture. However, most students and, perhaps, most people do not fully recognize what culture is and the span of its influences. The pervasiveness and seeming incomprehensiveness of cultural differences often surprise and unsettle the traveler, and his or her ability to adapt to the new culture may be one of the biggest contributors to a positive or negative experience abroad.

Culture is the set of norms, behaviors, attitudes, beliefs, values, customs, artifacts, language, and institutions of a particular group of people (Dodd 1987, Neulip 2000). It is learned and transmitted from generation to generation, unconsciously. Culture is learned and internalized at an early age and affects nearly everything people do. Because culture is constantly reinforced by others, people often do not recognize culture and cultural influences; they believe the way they think and act is natural or normal. Our culture teaches us viewpoints - ways of interpreting the world. When we cross cultures, it is often the first time we are confronted with differing viewpoints.

It is when people nurtured in such different psychological worlds meet that differences in cultural perspectives and communicative codes may sabotage efforts to understand one another. Repeated collisions between a foreigner and the members of a contrasting culture often produces what is called "culture shock." It is a feeling of helplessness, even of terror or anger, that accompanies [living] in an alien society. One feels trapped in an absurd and indecipherable nightmare. (Barnlund, 1994, p.34)

In situations of cultural differences, we are quick to judge, to blame, to label. The "other" is strange, rude, wrong, weird.

But, if we could change our viewpoint, our lens, perhaps we could better understand another point of view. Certainly, this is easier said than done. Our beliefs, values, and cultural perspectives are generally tacit and untested. Yet, with a model for deconstructing misunderstandings, we can bring our lens to a conscious level and attempt to understand other perspectives. 
The LENS tool does just that. In a simple process with a powerful visual, we can bring awareness to our own lenses and try on a new pair. While other models for intercultural understanding exist, the LENS tool utilizes intercultural competency knowledge, skills, and attitudes in a comprehensive, understandable and tangible technique.

\section{Review of Previous Techniques}

Previous researchers in intercultural communication and social psychology have proposed approaches to help people make sense of cultural differences intercultural misunderstandings. However, there is not a single model that fulfills the need to bring our lens to a conscious level and foster understanding other perspectives, nor is there a technique that is especially accessible, engaging, and doable, particularly for the visual, action-oriented, and socially-motivated millennial student.

\section{The DIE Exercise}

The Describe, Interpret, Evaluate, or DIE, exercise (Bennett and Bennett 1977) is a widely used method to teach cognitive and cultural awareness. The point of the exercise is to help people distinguish between objective descriptions, subjective interpretations, and emotional evaluations. The exercise is often conducted in intercultural training by using ambiguous objects or pictures initially and then moving forward using the steps to understand other cultural behaviors, events, or ideas.

In the Describe step, the individual provides a detailed description, including all of the observable details about the person/place/thing/idea/event/ behavior. The next step, Interpret, is to examine the gathered descriptions and interpret the significance in context. The final step, Evaluate, is to examine the situation by comparing with the values of the culture to person/place/thing/ event/behavior. The individual should be examining how the behavior aligns with the values and standards of the culture.

Of concern is that the distinction between "Interpret" and "Evaluate" is not always clear. In fact, some suggest that "even the teacher or trainer becomes confused when using these two words" (Nam \& Condon 2010: 84). Equally important is that the acronym does not lend itself to represent what is occurring through the process. Finally, this approach is not engaging or actionoriented enough for the millennial student.

\section{The Ladder of Inference}

The Ladder of Inference (Argyis, Putnam \& Smith 1985) describes the thinking process that individuals use, usually without realizing it, to get from 
a fact to a decision or action. The theory is based on the idea that thought processes and expectations are unconscious, biased, and self-generating.

The image of the ladder serves to make apparent the mental steps individuals take without realizing it. An individual begins at the base with Real Data $\&$ Experience. The first rung of the ladder represents a set of Selected Data \& Experience that he/she notices, because of past experiences, values, or beliefs.

Going up another rung of the ladder, he or she will then Affix Meaning to what has been selected to see, and will then develop Assumptions (third rung). These assumptions then become the basis for Conclusions (fourth rung). The individual then develops or reinforces Beliefs (fifth rung). These Beliefs then form the basis of Actions (top of the ladder). This creates a regenerating cycle: our beliefs have a large effect on the data we select from reality, and can lead us to ignore the facts altogether, thus reinforcing our beliefs. We are mentally jumping to conclusions as we climb up the ladder of inference.

There are various approaches to applying the Ladder of Inference in everyday life. One of the simpler approaches suggests:

- Becoming more aware of your own thinking and reasoning (reflection)

- Making your thinking and reasoning more visible to others (advocacy)

- Inquiring into others' thinking and reasoning (inquiry) (Senge et al. 1994:245)

The Ladder of Inference creates a nice visual, but the approaches are not particularly easy to remember or follow. It is quite abstract and theoretical, which makes it a solid foundation for understanding thinking and biases, but not an easy-to-implement model for intercultural misunderstandings.

\section{Reviewing Critical Events}

The reviewing critical event approach (Hess 1994) is intended to serve as an "instant replay" in which the person can review the incident and see it from different angles. The steps are:

1. Recognizing what a critical event is

2. Reconstructing the event

3. Getting more information about it

4. Making new interpretations and shaping new behavior because of it (Hess 1994:23). 
In the first step, recognizing the critical event, the goal is to identify a critical event to examine. In the next step, reconstructing the critical event, the foreigner retells the event as he or she experienced it, including both facts and feelings. In the getting more information step, the foreigner should enlist the help of a cultural informant to provide a different perspective, or an explanation from the other culture's point of view. In the final step, making new interpretations of the event, the foreigner reexamines the event (and the culture) with more clarity, and looks for ways to incorporate the knowledge into future interactions.

This approach is a valuable reflective tool, but does not necessarily bring awareness to one's own biases. Also, without an acronym or visual, it is not particularly assessable to the millennial student.

\section{Theoretical Background of the LENS Approach}

The LENS technique integrates research on experiential learning, intercultural competency, and millennial students. By utilizing experiential learning theory, the LENS approach allows students to transform the experiences they have abroad into knowledge by following the learning cycle. By incorporating intercultural competency research, the LENS technique allows students to hone the knowledge, skills, and attitudes needed for intercultural competency. And by examining the characteristics of millennial students, the LENS model appeals to students in its visual, accessible approach.

\section{Experiential Learning}

"For the things we have to learn before we can do them, we learn by doing them." Aristotle

Experiential learning is a "holistic, integrative perspective on learning that combines experience, perception, cognition, and behavior” (Kolb 1984:21). The theory posits that learning does not result from mental processes or behavioral processes alone, but through reflection and abstraction based on experiences. Kolbs (1984), states, "learners, if they are to be effective, need four different kinds of abilities.

Concrete experience abilities: They must be able to involve themselves fully, openly, and without bias in new experiences.

Reflective observation abilities: They must be able to reflect on and observe their experiences from many perspectives.

Abstract conceptualization abilities: They must be able to create concepts that integrate their observations into logically sound theories. 
Active experimentation abilities: They must be able to use these theories to make decisions and solve problems. (Kolb 1984:30)

Kolb believes that effective learning is a cyclical process: A Concrete Experience should lead to Reflection on that experience. This should then be followed by the mental creation of a set of general rules describing the experience (Abstract Conceptualisation). This should then lead to modifying or trying the newly formed "rules" called Active Experimentation which leads, in turn, to the next Concrete Experience.

Figure 1. Kolb's Learning Cycle
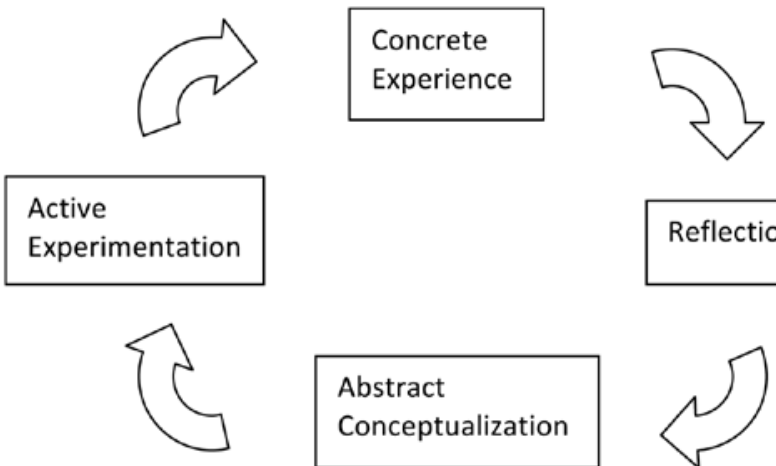

Active

Experimentation
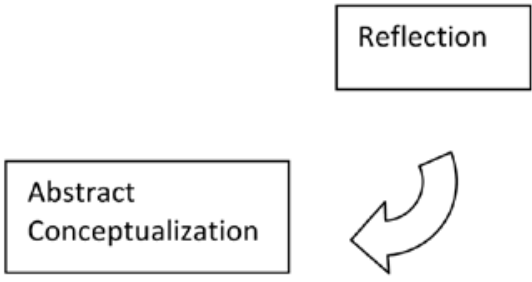

Kolb has further stated that individuals have learning "styles" or preferences; in other words, that they may be more comfortable with one of these activities than the others. As educators, it is therefore important to encourage students to develop and hone each of the abilities, even those that are not their "preferences."

Intercultural interactions are a prime example of an experiential learning activity, one in which students can gain knowledge through experience, if they also spend time reflecting, conceptualizing, and experimenting. A good model should help students hone each of the skills in Kolb's experiential learning cycle.

\section{Intercultural Knowledge and Competence}

Intercultural competence is generally defined as the knowledge, attitudes and behaviors needed to be culturally appropriate and effective (Gudykunst, Ting-Toomey \& Wiseman 1991, Kim 1991, Grunzweig \& Rinehart 1998, Deardorff 2004, J.M. Bennett 2008). However, assessing one's intercultural knowledge, attitudes, and behaviors has been complex and relatively non- 
standardized, until recently. In 2010, The Association of American Colleges and Universities (AAC\&U) published a rubric for Intercultural Knowledge and Competence. Developed by a team of faculty experts (Bennett, et al. 2011) from a range of colleges and universities, the rubric articulates six learning outcomes and performance descriptors from benchmark to capstone, with the goal of having a national framework of expectations for understanding student success.

The rubric defines Intercultural Knowledge and Competence as "a set of cognitive, affective, and behavioral skills and characteristics that support effective and appropriate interaction in a variety of cultural contexts" (Bennett 2008). The specific, measurable cognitive, affective, and behavioral characteristics, and their benchmark and capstone descriptors, are listed in Table 1.

Table1. Characteristics, Benchmarks, and Capstones of AAC\&U Intercultural Knowledge and Competence VALUE Rubric

\begin{tabular}{|l|l|l|}
\hline Characteristic & Benchmark & Capstone \\
\hline $\begin{array}{l}\text { Cultural self-awareness } \\
\text { (cognitive) }\end{array}$ & $\begin{array}{l}\text { Shows minimal } \\
\text { understanding of own } \\
\text { cultural rules and biases }\end{array}$ & $\begin{array}{l}\text { Articulates insight into own } \\
\text { cultural rules and biases, and } \\
\text { understands their complexity }\end{array}$ \\
\hline $\begin{array}{l}\text { Knowledge of cultural } \\
\text { worldview frameworks } \\
\text { (cognitive) }\end{array}$ & $\begin{array}{l}\text { Demonstrates surface } \\
\text { understanding of } \\
\text { elements of another } \\
\text { culture (history, values, } \\
\text { politics, communication } \\
\text { styles, economy, or } \\
\text { beliefs and practices) }\end{array}$ & $\begin{array}{l}\text { Demonstrates more } \\
\text { sophisticated understanding } \\
\text { of the complexity of } \\
\text { elements of another culture } \\
\text { (history, values, politics, } \\
\text { communication styles, } \\
\text { economy, or beliefs and } \\
\text { practices) }\end{array}$ \\
\hline Empathy (behavioral) & $\begin{array}{l}\text { Views experience of } \\
\text { others through own } \\
\text { cultural worldview }\end{array}$ & $\begin{array}{l}\text { Interprets experiences from } \\
\text { more than one worldview and } \\
\text { demonstrates ability to act } \\
\text { in a supportive manner that } \\
\text { recognizes the feelings of } \\
\text { another cultural group. }\end{array}$ \\
\hline $\begin{array}{l}\text { Verbal and non- } \\
\text { verbal communication } \\
\text { (behavioral) }\end{array}$ & $\begin{array}{l}\text { Has minimal } \\
\text { understanding of } \\
\text { cultural differences in } \\
\text { verbal and nonverbal } \\
\text { communication and is } \\
\text { unable to negotiate a } \\
\text { shared understanding }\end{array}$ & $\begin{array}{l}\text { Articulates a complex } \\
\text { understanding of cultural } \\
\text { differences in verbal and } \\
\text { nonverbal communication and } \\
\text { is able to skillfully negotiate a } \\
\text { shared understanding based } \\
\text { on those differences. }\end{array}$ \\
\hline Openness (affective) & $\begin{array}{l}\text { States minimal interest } \\
\text { in learning more about } \\
\text { other cultures. }\end{array}$ & $\begin{array}{l}\text { Asks complex questions about } \\
\text { other cultures, and seeks out } \\
\text { and articulates answers to } \\
\text { these questions that reflect } \\
\text { multiple cultural perspectives. }\end{array}$ \\
\hline $\begin{array}{l}\text { Is open to interactions } \\
\text { others but unaware of } \\
\text { own judgment }\end{array}$ & $\begin{array}{l}\text { Initiates and develops } \\
\text { interactions with culturally } \\
\text { different others and suspends } \\
\text { judgment in valuing her/his } \\
\text { interactions. }\end{array}$ \\
\hline
\end{tabular}


The Intercultural Knowledge and Competence rubric provides a solid foundation of the cognitive, behavioral, and affective characteristics necessary for effective and appropriate intercultural interactions. Thus, a good model should include opportunities for students to utilize and hone these characteristics.

In addition, in her Intercultural Competence model, Deardorff (2008) has also stressed the importance of skills such as listening and observing. She notes these skills are vital for individuals to be able to recognize what is occurring in intercultural situations. These skills also provide the foundation for individuals to acquire and apply additional cultural knowledge and skills. As such, observation "is an essential skill and key starting point" (44).

\section{Millennial Students}

Recent research has focused on the unique personalities, learning styles, and characteristics of Millennial Students (also called the iGeneration, Y Generation, and net generation), those students born between 1980 and 2000, and how they differ from previous generations (Johnson \& Romanello 2005, Rosen 2010). Among the most noticeable characteristics are their orientation toward visual learning, using technology and multi-tasking. These students are typically very comfortable with technology, have shorter attention spans and a low threshold for boredom (Kipnis \& Childs 2004, Johnson \& Romanello 2005, Rosen 2010). Rosen (2010), states, "the iGeneration is a creative, multimedia generation" (218). They "can deal with lots of information but prefer it packaged in short, focused segments" (Ricigliano 1999:124).

Thus, because this generation is visual, creative and reliant on multimedia, a good model should invoke imagery and be adaptable to multiple media. The symbolism and visual of a "lens" helps students connect with the overall point of the model. Reinforcing that we do not view the world objectively, but through our cultural (and personal) lenses is an important task.

In addition, students in this generation recognize the value of education (Tulgan and Martin 2001, Goldgehn 2004), but resist memorization and busy work, and learn best through doing and discovering (Mangold 2007). They are action-oriented and tenacious (Zemke 2001, Goldgehn 2004). They learn best when engaged and actively involved in their own learning, and when using a trial and error approach (Kipnis \& Childs 2004, Rosen 2010). Therefore, a good model should include steps that encourage students to reflect on and experiment with different approaches and action steps.

Finally, this generation thrives on social interaction, both real life and screen life (Rosen 2010). They are socially-oriented, placing a strong emphasis on family and relationships (Zemke 2001, Goldgehn 2004). This generation 
learns through engagement (Kipnis \& Childs 2004). Therefore, a good method for intercultural understanding should involve interacting with people.

\section{Examine your LENS}

The Examine your LENS method is a unique, specific, easy-to-remember approach involving four steps to make sense of intercultural misunderstandings. These steps are grounded in experiential learning theory and utilize the skills, attitudes, and perspectives needed for intercultural competence. By walking through these four steps, not only can we recognize our biases and understand a different perspective, but we can also actively engage with the local culture and experiment with trying on these new lenses.

\section{Look objectively}

Research indicates that we do not see the world objectively, but through cultural conditioning; however, we do not generally realize that we are not viewing the situation objectively. "Statements of fact, inference, and judgment are too often conflated" (Nam and Condon 2010:83). Therefore, for the first step, individuals need to try to separate the facts from the inference and judgments by describing the situation as objectively as possible. The instructions for this step are:

You are not viewing the encounter or event neutrally, but interpreting it through your expectations and judgments, which are often conditioned by your culture. Eliminate judgmental words, and describe the encounter or event objectively.

This step reflects Kolb's Concrete Experience, learning from real-life experiences and interactions with people. This also encourages individuals to recognize that they are in a learning moment and to employ the listening and observation skills noted by Deardorff (2008).

\section{Examine your assumptions}

Once the situation is described objectively, individuals can then examine the rationale, thought processes, and judgments they used to reach their conclusions. Thus, in the LENS model, step two is to "Examine your Assumptions." The instructions for this step are:

Be open-minded and curious, and look carefully at the assumptions you've made to see what values, habits, beliefs, and other cultural influences have led you to view the encounter or event as you did. 
This step allows students to hone Kolb's second ability, the Reflective Observation ability: taking time to reflect before making a judgment by viewing the environment and looking for the meaning of things. Furthermore, it encourages the individual to employ cultural self-awareness to uncover the rationale and thought processes used, and curiosity and openness (from the Intercultural Knowledge and Competence rubric) to question their own assumptions. It also draws on the millennial students' strength of being actively involved in their own learning.

\section{Note other possibilities}

After individuals have recognized the assumptions, attitudes, and presuppositions that have led to their conclusions, they should try to ponder other possibilities. This step is missing from previous approaches, but I believe it is very important. Before asking others, the individual should take time to consider other scenarios themselves. This achieves several things:

1. By reflecting, the individual slows down the emotional reaction, and takes time to try and process the situation. This teaches selfand other-awareness, empathy, and critical thinking skills.

2. By considering other possibilities, the individual learns to think with openness and curiosity.

3. With this openness and curiosity, the individual can approach another person more genuinely, rather than defensively.

Thus, the third step is to consider other ways of viewing the situation and other factors that may be at hand. It encourages people to consider things they had not previously noticed. The instructions are:

Be flexible and use your knowledge of the culture to envision what other values, habits, and beliefs might be at work here, and how they might lead to a different conclusion.

This step hones Kolb's abstract conceptualization ability, or logical analysis of ideas and intellectual understanding of a situation. This step also encourages the individual to use knowledge of cultural worldview frameworks and empathy (from the Intercultural Knowledge and Competence rubric) to consider other possible meanings and interpretations. Finally, this step reflects the millennial generation's desire to be actively involved in their own learning, to experiment and use trial and error. 


\section{Substantiate with Locals}

The final step is to substantiate with locals, to better understand the scenarios and use the cultural information in future interactions. This step is very important, to ensure that the individual recognizes the cultural components at work, and to learn how better to respond in the future. Enlisting the help of others can provide background and insight about the event, can bring awareness to aspects not even noticed, and can provide a more nuanced explanation about the event. The instructions for this step are:

Use your intercultural communication skills, critical thinking skills, and people skills to ask locals or bicultural people if the new possibilities you've generated are accurate, or if there are other parts of the culture you've overlooked.

This step hones Kolb's fourth skill set, active experimentation: acting by applying analysis and influencing people and events. This step also encourages the individual to use intercultural communication skills, curiosity, and openness (from the Intercultural Knowledge and Competence Rubric) to interact with locals to gain more information. Finally, this step reflects the millennial generation's desire to socialize and engage in order to learn. Table 2 demonstrates how each step is connected to Kolb's Learning Abilities, the Intercultural Knowledge and Competence rubric, and the Millennial Generation characteristics.

Table 2. LENS steps and Their Correspondence to Kolb's Learning Abilities, Intercultural Competence, and Millennial Generation

\begin{tabular}{|l|l|l|l|}
\hline Step & $\begin{array}{l}\text { Kolb Learning } \\
\text { Ability }\end{array}$ & $\begin{array}{l}\text { Intercultural } \\
\text { Competence } \\
\text { Component }\end{array}$ & $\begin{array}{l}\text { Millennial Generation } \\
\text { Characteristics }\end{array}$ \\
\hline $\begin{array}{l}\text { Look } \\
\text { Objectively }\end{array}$ & $\begin{array}{l}\text { Concrete } \\
\text { Experience }\end{array}$ & Observation \\
\hline $\begin{array}{l}\text { Examine Your } \\
\text { Assumptions }\end{array}$ & $\begin{array}{l}\text { Reflective } \\
\text { Observation }\end{array}$ & $\begin{array}{l}\text { Cultural Self-Awareness } \\
\text { Curiosity } \\
\text { Openness }\end{array}$ & $\begin{array}{l}\text { Actively involved in their } \\
\text { own learning }\end{array}$ \\
\hline $\begin{array}{l}\text { Note Other } \\
\text { Possibilities }\end{array}$ & $\begin{array}{l}\text { Abstract } \\
\text { conceptualization }\end{array}$ & $\begin{array}{l}\text { Knowledge of cultural } \\
\text { worldview frameworks } \\
\text { Empathy }\end{array}$ & $\begin{array}{l}\text { Actively involved in their } \\
\text { own learning } \\
\text { Learn through trial and } \\
\text { error }\end{array}$ \\
\hline $\begin{array}{l}\text { Substantiate } \\
\text { with Locals }\end{array}$ & $\begin{array}{l}\text { Active } \\
\text { Experimentation }\end{array}$ & $\begin{array}{l}\text { Intercultural } \\
\text { communication skills } \\
\text { Curiosity }\end{array}$ & $\begin{array}{l}\text { Learn through socializing } \\
\text { Engaging } \\
\text { Doing }\end{array}$ \\
\hline
\end{tabular}




\section{Applying "Examine your LENS"}

At Texas Christian University (TCU) we introduce students to the "Examine your LENS" tool during pre-departure orientation sessions and encourage them to use the technique while abroad. We have been able to collect a small sample of written data about how students are employing "Examine your LENS" from the following method. TCU students have the option to complete one of TCU's general studies requirements, Cultural Awareness, while studying abroad. In order to attain the Cultural Awareness requirements, students must take part in a pre-departure lecture (which includes information about cultural learning and the LENS steps), read several selected pieces on cultural adaptation, and write two essays while abroad, responding to the predeparture information and writing prompts, such as

Reflect on an emotional encounter, a miscommunication, or a

frustration. Now that you are away from the moment, can you identify

more clearly what led to the situation? What were you expecting to happen, and what actually happened? Is this a cultural norm that you misunderstood? What was your role in the misunderstanding?

The following essays were submitted by TCU students during their time abroad. Although the students were not asked to label each step in the essay, it is easy to see how they are moving through the steps of Examine your LENS.

The following essay is from Michael Vosters, who studied with TCU in Seville in Spring 2010. The left column notes the LENS steps.

In this incident, Michael begins by venting his frustration with his señora, in particular with the loudness of her voice (her "yelling") and the topic of her complaints (open the door; pick up your shoes). As he begins to process the incident, he works through the steps of examining his LENS, with the following conclusions:

Look Objectively: He describes the many things she does to take care of him, "She does just about everything for my roommates and I - cooks, cleans, launders, and loves us as if we were her own sons."

Examine Your Assumptions: He recognizes that he does not understand her "set of priorities." First, by admitting he does not understand her priorities he acknowledges that he is governed by a set of priorities or principles or values. Second, by calling them priorities he takes the first step in acknowledging that they are important to her, even if not to him.

Note Other Possibilities. He clearly delineates what he imagines her priorities may be, including: 
1. Because there's no air conditioning in Spain, therefore they depend on air circulation.

5. Because humidity from showering can get stinky without ventilation.

6. Because feet and outdoor shoes track dirt and grime, hence dirtying the floor.

By taking the time to think through her rationale, and why she is concerned about the things she is, he can better understand her and relate to her. He can also interact with her in a calmer way now as he moves on to Substantiate with Locals. Although his actual interaction is not described we see the end result as he lists a number of things he better understands, including:

Manoli's job is to take care of students while they stay in Sevilla. Her house is her office, and she takes pride in it.

We had to show respect. Now, respect isn't just saying please and thank you - especially in Spain as that indicates a sign of formality and distance - it's about recognizing the other person's needs and priorities and acting accordingly.

By moving through the steps of Examine your LENS, Michael was able to recognize his cultural assumptions and presuppositions, as well as Manoli's, in order to come to a better understanding of her behavior and their interactions.

The following essay is from Courtney Benson, who studied with CIEE in Shanghai in Fall 2010. 


\section{Look Objectively}

Examine Your Assumptions

Note Other Possibilities

Substantiate with Locals
This is going to sound incredibly shallow as I say it, but the thing that really threw me off the most was waiting in lines in China. In Texas (where l'm from), there is little if any cutting in lines (excluding when the roads). In China, it could also be argued that there is no cutting in lines, but that's mostly because it could be argued that there are no 'lines' as people generally refer to them. People crowd around counters or cashiers in deceptively line like arrangements, but if there is the smallest gap between people, someone else will fill it. It doesn't matter how long a person has waited, if they aren't aggressive enough to fight to get to the cashier, they won't be able to accomplish anything. In a similar vein, when people are walking from one place to another, they just walk, and if they bump people, no matter. I have yet to find a way to say "excuse me" to indicate that I need to pass someone, or 'pardon me' to apologize for bumping into someone. These things are never said, and I was apparently the only person expecting them need. In the beginning, these things alternately baffled and enraged me; I felt that my time and rights as a person ought to be respected. I viewed their behavior towards me as a slight, thinking that they were just too busy or self-centered to notice that someone else had needs too, and for a while I let that begin to color my view of the Chinese people as a whole. If this was how they treated strangers (the very people Southerners are socially obligated to show deference to), how could they treat each other better? It took an unfortunate adventure on the subway to show me how narrow-minded that really was.

I was trying to catch a subway and for whatever reason, the escalator was out-of-order; I was walking up it when I heard my train coming and began to run up the escalator. About half way up, I lost my footing and somehow managed to slam both of my big toes ( 1 was wearing flip-flops) on the edge of the escalator teeth; it hurt, but I had to keep going. Luckily, I made the subway on time and turned to tend my toes; I expected they would be a little red and sore, so when I looked down at blood pooling in my sandals, I was a bit shocked. I really didn't know what to do; I was leaving little puddles of blood on the subway floor; I had no band-aids or napkins, and there was no way to get them on the subway. But, the Chinese people around me weren't as lost. I was standing next to a group of girls, and when they realized I was hurt, two of them pulled tissues and band-aids to help me; a lady sitting nearby gave up her seat so that I could better tend my feet. And when I got off, the little old lady who saw me struggling to get down the stairs would not take no for an answer as she gave me another band-aid and refused to even let me put it on myself. And THAT kind of generosity is far beyond what most Southerners could muster. As I ruminated on this, I was forced to re-evaluate my perception of the Chinese people.

I come from a culture and family where 'proper manners' are extremely important, and 'proper manners' include things like opening doors for others, forming and respecting neat lines, and apologies for jostling people. But, what if when genuinely kind people don't do these things? I can't say that l've found the source of such marked cultural differences (though I do have a few ideas), but I can say that as I have spent more time here, I have come to really believe (in practice, not just principle) that differences are not deficiencies. 
Courtney's essay describes her frustration with the lack of lines. While recognizing that it is "shallow," she realizes she is taking a seemingly minor situation and making major judgments thinking the Chinese people were "too busy or self-centered to notice that someone else had needs too."

Look Objectively: She recognizes that there are no lines per say, but that aggression is the way to move forward.

People crowd around counters or cashiers in deceptively line like arrangements, but if there is the smallest gap between people, someone else will fill it. It doesn't matter how long a person has waited, if they aren't aggressive enough to fight to get to the cashier, they won't be able to accomplish anything.

Examine Your Assumptions: She is "baffled and enraged" that others do not say "excuse me" or "pardon me," and then realizes that "I was apparently the only person expecting them" - in other words, that it was not a part of their cultural norms.

Note Other Possibilities. It takes a different kind of situation, stubbing her toe and receiving help from others, before she begins to see generosity take shape in different ways. She recognizes there is a difference in how kindness is displayed:

I come from culture and family where 'proper manners' are extremely important, and 'proper manners' include things like opening doors for others, forming and respecting neat lines, and apologies for jostling people. But, what if when genuinely kind people don't do these things?

Substantiate with Locals. Although she does not substantiate with locals explicitly, she does recognize that "differences are not deficiencies."

By moving through the steps of Examine your LENS, Courtney recognized that a value important to her was also important to her host culture, but displayed in a different way.

\section{Future Applications}

We are exploring a number of applications for presenting the LENS technique to students and encouraging them to move through the steps. Of particular interest is an application for iPhones and other android devices. We recognize that students rely on technology and are used to instant access and easy accessibility. Apps for phones and other portable computer technology let a student find what they are looking for quickly and provide an interactive functionality. 
We are also exploring ways to use a LENS logo. The visual provides an immediate reminder of the LENS approach, and even if students do not take the time to move through each of the LENS steps, the visual reinforces that they are interpreting events through their personal "lens" and to be aware that there are other interpretations. Finally, we have several curricular enhancements to our study abroad programs including, as noted previously, a Cultural Awareness option and a one-credit hour on-site course. Through both of these mechanisms, we are integrating an assignment using the LENS technique.

Future research will hopefully confirm the anecdotal remarks from students that the technique is easy to employ and truly aids in intercultural understanding. As one student wrote,

"I love the LENS approach...especially the "Substantiate with locals"...I

find that the most valuable way to experience any culture...it only makes sense.” Lyndsey Evans

\section{Summary}

The technique, Examine your LENS, provides a new tool for individuals crossing cultures, by providing a mnemonic device, a specific set of steps and a mental image. Founded in experiential learning theory and utilizing the components of intercultural knowledge and competence, the steps remind individuals to look more objectively at situations, examine their own assumptions and expectations, note other possible values, habits, and expectations, and substantiate possible interpretations with locals. The imagery of recognizing that we all have a cultural lens, or bias, which shades our view of events, incidents, and people, is equally important.

Experiential learning theory posits that four skill sets or abilities are necessary for meaningful learning to result from experiences. Intentionally performing "Concrete Experience," "Reflective Observation," "Abstract Conceptualization," and "Active Experimentation" leads to more transformational learning. As such, the LENS technique provides opportunities for individuals to utilize each of these skills.

Intercultural Competency research indicates there are essential cognitive, affective, and behavioral skills and characteristics which are essential for effective and appropriate interactions. In 2011, AAC\&U created a rubric defining these skills and characteristics: cultural self-awareness, knowledge of cultural worldview frameworks, empathy, verbal and non-verbal communication, curiosity, and openness. The LENS method provides opportunities for students to utilize each of these characteristics. 
Finally, recent research on the millennial student shows that their learning styles are different from previous generations, and should be accommodated for maximum learning. Specifically, this generation has a shorter attention span and likes information packaged in short segments. They are creative and visual, reliant on imagery and multi-media. They like to learn, but learn best through doing and discovering. They thrive on social interaction, and learn best through engagement. The LENS technique provides imagery as well as steps for learning through discovery, action, and engagement with others.

The Examine your LENS method is a unique, straightforward, memorable technique of four steps to understanding intercultural interactions. These steps are grounded in experiential learning theory and utilize the skills, attitudes, and perspectives needed for intercultural competence. By walking through these four steps, not only can we recognize our biases and understand a different perspective, but we can also actively engage with the local culture and experiment with trying on these new lenses. As educators who want our students to be actively involved in their own learning, self-aware, and engaged in the local culture, this technique is an ideal tool.

\section{References}

Argyris, C., Putnam, R. \& McLain Smith, D. (1985). Action Science. San Francisco: Jossey-Bass.

Barnlund, D. (1994). Communication in a Global Village. In L. Samovar \& R. Porter (Eds.) Intercultural Communication: A Reader (26-36). Belmont, CA: Wadsworth Publishing Company.

Bennett, J.M., Bennett, M. and Stillings, K. (1977). DIE Exercise. Retrieved from www.intercultural.org.

Bennett, J. M. (2008). Transformative training: Designing programs for culture learning. In M. A. Moodian (Ed.) Contemporary leadership and intercultural competence: Understanding and utilizing cultural diversity to build successful organizations (95-110). Thousand Oaks, CA: Sage.

Bennett, J. M., Brown, K., Cartwright, C., Davis, M., Deardorff, D., Hearn-Chung Gin, D., Huston, C., Knefelkamp, L., Nishishiba, M., and Smith, D. G. (2010). AAC\&U Intercultural Knowledge and Competence Value Rubric. In Rhodes, T. (Ed.) Assessing Outcomes and Improving Achievement: Tips and Tools for Using Rubrics. Washington, DC: Association of American Colleges and Universities.

Deardorff, D. K. (2008). Intercultural competence: A definition, model, and implications for education abroad. In V. Savicki (Ed.) Developing Intercultural Competence and Transformation $(32-52)$. Sterling, VA: Stylus Publishing. 
Deardorff, D. K. (2004). The Identification and Assessment of Intercultural Competence as a Student Outcome of Internationalization at Institutions of Higher Education in the United States. (Doctoral dissertation). Raleigh, NC: North Carolina State University.

Dodd, C. (1987). The dynamics of intercultural communication. Dubuque, IA: Wm. C. Brown Publishers.

Goldgehn, L.A. (2004). Generation who, what, Y? What you need to know about Generation Y. International Journal of Educational Advancement 5 (1), $24-34$.

Grunzweig, W. \& Rinehart, N. (1998). International Understanding and Global Interdependence: A philosophical inquiry. International Educator, Fall, 41-48.

Gudykunst, W., Ting-Toomey, S. \& Wiseman, R. (1991). Taming the Beast: Designing a course in intercultural communication. Communication Education, 40, 272-285.

Hess, J. D. (1994). The Whole World Guide to Culture Learning. Intercultural Press: Yarmouth, ME.

Johnson, S.A. and Romanello, M.L. 2005. Generational Diversity: Teaching and learning approaches. Nurse Educator 30 (5), 212 - 216.

Kipnis, D. G. \& Childs, G. M. (2004). Educating Generation X and Generation Y: Teaching tips for librarians. Medical Reference Services Quarterly 23 (4), 25 - 33.

Kim, Y. (1991). Intercultural communication competence: A systemstheoretic view. In S. Ting-Toomey \& F. Korzenny (Eds.) Crosscultural interpersonal communication (259-275). Newbury Park: Sage Publications.

Kolb, D. (1984). Experiential Learning: Experience as the source of learning and development. Upper Saddle River, NJ: Prentice Hall.

Mangold, K. (2007). Educating a new generation: Teaching baby boomer faculty about millennial students. Nurse Educator 32 (1), 21 - 23.

Nam, K-A \& Condon, J. (2010). The DIE is cast: The continuing evolution of intercultural communication's favorite classroom exercise. International Journal of Intercultural Relations 34, 81 - 87.

Neulip, J. (2000). Intercultural Communication: A Contextual Approach.

Boston: Houghton Mifflin Company.

Rosen, L. D. (2010). Rewired: Understanding the iGeneration and the Way

They Learn. New York: Palgrave Macmillan.

Senge, P. M., Kleiner, A., Roberts, C., Ross, R. B., \& Smith, B. J. (1994).

The Fifth Discipline Fieldbook. New York: Currency Doubleday.

Smith, M. K. (2001). David A. Kolb on experiential learning. The 
Encyclopedia of Informal Education. Retrieved from http://www.infed. org/biblio/b-explrn.htm.

Tulgan, B. \& Martin, C. A. (2001). Managing Generation Y: Global Citizens born in the Late Seventies and Early Eighties. Amherst, MA: HRD Press.

Zemke, R. 2001. Here come the Millennials. Training 38 (7), $44-49$. 